\title{
ПСИХОЛОГИЧЕСКАЯ СТРУКТУРА МЕЖЛИЧНОСТНОГО КОНФЛИКТА
}

Дубовицкая Т.Д.

Придя в психологию из философии и социологии понятие «конфликт» до сих пор сохранило категориальный аппарат данных наук. Психологически ориентированная традиция в конфликтологии предполагает формулирование максимально психологического содержания сущности конфликта, что необходимо для разработки технологий его управления и предотвращения в целях снижения социальной напряженности в обществе.

Особый интерес представляет исследование межличностного конфликта, как наиболее распространенного и являющегося, как основой, так и содержанием других видов социального конфликта. Есть все основания утверждать, что практически все виды социальных конфликтов имеет в своей основе деструктивные межличностные отношения их участников.

Что касается определения понятий «конфликт»/«межличностный конфликт», то как показывает анализ, значительное число их определений базируется на философско-социологическом категориальном аппарате. В частности, существующие на сегодняшний день авторские определения межличностного конфликта содержат в качестве основополагающих два следующих понятия: 1) «столкновение» (тенденций, целей, позиций, мнений, взглядов и др.) конфликтующих (сторон, партнеров, индивидов, групп) (А.Г. Здравомыслов, А.А. Урбанович, М.Р. Душкина, В.И. Курбатов и др.); 2) «противоречие» (в виде столкновения, борьбы, противостояния, противодействия) (Е.М. Бабосов, С.М. Кашапов, Б.И. Хасанов, Н.И. Леонов, А.Я. Анцупов, А.И. Шипилов и др.). Оба этих понятия требуют дополнительного раскрытия своего содержания, поэтому не могут быть, по нашему мнению, выступать основополагающими при определении психологической сущности конфликта.

На специфическую психологическую сущность конфликта указывают, в частности Д. Майерс, а также В. Шейнов. Согласно Д. Майерсу: «Конфликт это воспринимаемая несовместимость действий или целей» [1, с.287]; по мнению В. Шейнова: «Конфликт - это столкновение, противоборство сторон, при котором хотя бы одна сторона воспринимает действия другой как угрозу ее интересам» [2, с.10]. Причем, в определении В. Шейнова мы также видим ранее названные понятия «столкновение», «противоборство», которые в целях практико-ориентированной конфликтологии опять же требуют дополнительных разъяснений.

Психологическое определение межличностного конфликта может исходить из следующих положений:

1) конфликт, как правило, предполагает общение (непосредственное или опосредованное) его участников в структуре которого, в частности, принято выделять три стороны: коммуникативную, перцептивную, интерактивную;

2) источником активности личности, в том числе и в ситуации конфликта, выступают определенные потребности; 
3) в отличие от бесконфликтного общения для конфликтного общения характерно переживание его участниками негативных эмоциональных состояний и чувств по отношению друг к другу.

В этой связи можно дать следующее определение: конфликт - это негативно пережсиваемое субъектами общения взаимодействие, возникающее в связи с восприятием действий друг друга, как представляющих угрозу удовлетворению их значимых потребностей.

Согласно представленному определению, конфликт относится к проявлениям интерактивной стороны общения, как процесса установления и развития контактов между людьми. В центре конфликта находятся проблема угрозы удовлетворения значимых потребностей субъектов взаимодействия и связанные с этим эмоции.

Психологический анализ конфликта предполагает выявление его макро и микроструктуры. Макроструктура конфликта охватывает всех участников конфликта, а также их окружение и включает следующие компоненты.

1. Объективные составляющие конфликта: стороны (участники) конфликта; объект конфликта; предмет конфликта; действия участников конфликта; микросреда, в которой он развивается; макросреда, оказывающая влияние на ход конфликта; вид конфликта.

2. Субъективные составляющие конфликта: образы конфликтной ситуации в сознании ее участников, включая образ оппонента, самого себя, вероятных результатов борьбы; мотивы действий сторон; цели, которые они преследуют; актуальные психические состояния участников (включая страхи и опасения).

3. Функиионально-динамические составляюшие конфликта: стадии протекания конфликта; стратегии поведения конфликтующих; конструктивные и деструктивные функции конфликта.

Используя данную макроструктуру конфликта можно проанализировать практически любой межличностный и даже межгрупповой конфликт и выйти на поиск путей их разрешения и управления в целом, включая профилактику, прогнозирование, диагностику. Для выявления макроструктуры конфликта желательно получение информации от свидетелей конфликта.

Микроструктура межличностного конфликта касается анализа поведения, мыслей и переживаний каждого из участников в отдельности и включает в себя:

1) интерактивныци компонент - действия субъектов, направленные на удовлетворение потребностей и защиту своих интересов;

2) когнитивный компонент - мысленное восприятие действий другого как угрожающих удовлетворению потребностей, в том числе поддержанию позитивной самооценки;

3) негативные эмоции по отношению друг к другу (как следствие неудовлетворения или страха неудовлетворения потребностей) - аффективный компонент.

Интерактивный компонент представлен действиями и поступками конфликтующих по отношению друг к другу. В ситуации случайных 
конфликтов - человек совершает действия, направленные на удовлетворение собственных потребностей, не учитывая при этом потребности других людей. В ситуации намеренных конфликтов, эти действия заключаются в целенаправленном стремлении нанести моральный, материальный, физический ущерб другому.

Аффективный компонент отражает то, что чувствуют, переживают конфликтующие по поводу происходящего, в том числе и по отношению друг к другу. Как правило, это отрицательные эмоции, вызванные блокировкой удовлетворения потребностей человека. Это могут быть гнев, негодование, возмущение, огорчение, обида и др. Чем более значимые потребности человека задеваются, чем более затрудняется их удовлетворение, тем более сильные негативные эмоции он испытывает. В частности, угроза жизни и даже самооценке человека могут вызвать состояние аффекта, провоцирующее человека на серьезные защитные действия вплоть до физической агрессии по отношению к обидчику.

Когнитивный компонент включает мысли и убеждения субъектов, имеющие отношение к конфликтам. Конфликт возникает тогда, когда действия другого/других воспринимаются как несущие опасность здоровью, самочувствию, самооценке человека или значимым для него людям. Подобное восприятие может быть объективным, строиться на основе реальных фактов, или же быть полностью надуманным, приписываться человеку, исходя из своего жизненного опыта (порой ограниченного), внешнего настроя, а также уровня воспитанности (культуры), носить характер проекции, провоцироваться болезненным состоянием.

Как правило, только наличие всех трех составляющих микроструктуры конфликта, проявляющихся у всех конфликтующих по отношению друг к другу, свидетельствует о реальном конфликте. В остальных случаях можно говорить о конфликтной ситуации, напряженности в отношениях разной степени. Разделение конфликта и конфликтной ситуации принципиально важно. Так как порой напряженная (конфликтная) ситуация может длиться годами, не перерастая в открытый конфликт (переживаться на уровне внутриличностного конфликта: нужно изменить ситуацию, но не хочу; хочу изменить ситуацию, но не могу и др.), но обеспечивая ее участникам или одному из них хронический стресс, который рано или поздно скажется на его соматическом здоровье.

Представленные компоненты микроструктуры конфликта имеют принципиальное значение для практической консультативной и коррекционной работы, которая предполагает в ходе работы с конфликтующими:

1) выявление/актуализацию потребностей каждой из сторон (чего хотят они друг от друга и от психолога);

2) выявление и последующее изменение (в случае необходимости) их перцептивных установок, взглядов, конфликтогенных убеждений (именно их коррекция может являться центральным звеном в урегулировании конфликтов);

3) регуляцию и саморегуляцию эмоционального состояния (возможно через осознание ценности душевного равновесия и др. техники); 
4) поиск конструктивных способов взаимовыгодного удовлетворения потребностей (например, через обучение различным формам поведения).

Данные структурные модели конфликтов универсальны и применимы для анализа как супружеских, так и детско-родительских, организационных и других категорий социальных конфликтов. Использование данных моделей в образовательном процессе в курсе преподавания конфликтологии - как учебной дисциплины позволяет организовать групповую интерактивную работу обучающихся, повышает их вовлеченность в образовательный процесс, позволяет осознать собственные межличностные конфликты и обозначить пути их разрешения.

\section{Литература}

1. Майерс Д. Социальная психология в модулях. - СПб.: Прайм - ЕВРО ЗНАК, $2006-318 \mathrm{c}$.

2. Шейнов В. Управление конфликтами. - СПб.: Питер, 2014. - 576 с.

\section{ПРОБЛЕМА ЛИЧНОСТИ В СПОРТИВНОЙ ПСИХОЛОГИИ Мельников В.М., Юров И.А.}

Публикаций по психологии личности достаточно много. Однако существуют и проблемы: 1.В литературе не представлена отечественная парадигма психологии личности. 2. Понятие личности трактуется от очень узкого до самого широкого понимания. 3. Одни психологи особенно подчеркивают социальные компоненты, а другие - биологические компоненты личности.4. При экспериментальном описании психологии личности практически не учитываются возрастные, квалификационные, гендерные особенности. 5. Много работ по отдельным уровневым подструктурам личности, но очень мало - комплексных описаний психологии личности.

Традиционно в отечественной психологии под структурой личности понимается четырехкомпонентная модель, включающая в себя темперамент, характер, направленность личности, способности (Рубинштейн С.Л.,П.А.Рудик, А.Ц.Пуни, Е.П.Ильин, А.В.Родионов и др.). Значительный ряд спортивных психологов, беря за основу трактовку понятия личности зарубежных авторов (например, Г.Оллпорта, А.Маслоу, Э.Берна и др.), тем не менее, содержание понятия и структуру личности раскрывают через представления отечественных психологов, которые в корне отличаются от зарубежных. В результате получается некая эклектика элементов, не связанная ни с теоретическими, ни с методологическими, ни с методическими позициями зарубежных и отечественных психологов. Раскрывать содержания понятия и структуру личности целесообразно в рамках единой научной концептуальной модели. Описание личности только по одной подструктуре или одному компоненту не является полной и комплексной и фактически ничего не дает ни для теории, ни для практики, в частности спорта.

В отечественной психологии сложился целый ряд школ и направлений, в которых психические свойства личности (личностные свойства) исследуются в разных аспектах. Одни психологии рассматривают личность в связи с анализом 